\title{
Novo padrão brasileiro de rotulagem de alimentos embalados: modelos, discursos e controvérsias
}

New Brazilian standard for food package labeling: models, discourses, and controversies

Nueva norma brasileña para el etiquetado de alimentos envasados: modelos, discursos y controversias

Lucas de Vasconcelos Teixeira

- Doutorando do Programa de Pós-Graduação em Comunicação e Práticas de Consumo da Escola Superior de Propaganda e Marketing (ESPM-SP).

- $\quad$ Mestre em Comunicação e Práticas de Consumo pela ESPM-SP.

- Bolsista Capes-Prousp.

- Membro do Grupo de Pesquisa Comunicação, discursos e biopolíticas do consumo (Biocon).

- $\quad$ E-mail: lvteixeira@gmail.com

\section{(9) Tânia Márcia Cezar Hoff}

- Professora titular do Programa de Pós-Graduação em Comunicação e Práticas de Consumo da ESPM-SP.

- Doutora em Letras pela Faculdade de Filosofia, Letras e Ciências Humanas da Universidade de São Paulo (FFLCH-USP).

- Coordenadora do Grupo de Pesquisa Biocon, da Cátedra Maria Aparecida Baccega e do Comitê de Ética em Pesquisa da ESPM.

- E-mail: thoff@espm.br 


\section{Resumo}

0 objetivo deste artigo é examinar as disputas sobre o novo padrão de rotulagem nutricional brasileiro. A empiria é composta por entrevistas concedidas por representantes de entidades vinculadas à indústria alimentícia ou sociedade civil. A metodologia é a análise de conteúdo. Os resultados reverberam para além dos rótulos, envolvendo relações de poder, discursos e produção de verdades. A controvérsia entre comida natural e ultraprocessada permeia esses discursos, cada qual buscando legitimar suas próprias verdades.

PALAVRAS-CHAVE: ROTULAGEM DE ALIMENTOS • DISPUTAS DISCURSIVAS • RELAÇÕES DE PODER • COMUNICAÇÃO ORGANIZACIONAL・ANÁLISE DE CONTEÚDO.

\section{Abstract}

This article aims to examine the disputes over the new Brazilian nutrition labeling model based on interviews with representatives of entities connected to the food industry or civil society. Data underwent content analysis, and the results reverberate beyond the labels, involving power relations, discourses, and production of truths. These discourses address the controversy between natural and ultra-processed food, each seeking to legitimize its own truths.

\section{KEYWORDS: FOOD LABELING • DISCURSIVE DISPUTES • POWER RELATIONS • ORGANIZATIONAL COMMUNICATION • CONTENT ANALYSIS}

\section{Resumen}

Este artículo se propone analizar las disputas sobre el nuevo modelo brasileño de etiquetado nutricional. El corpus se compone de entrevistas concedidas por representantes de entidades vinculadas a la industria alimentaria o la sociedad civil. La metodología es el análisis de contenido. Los resultados repercuten más allá de las etiquetas, ya que involucran relaciones de poder, discursos y producción de verdades. La controversia entre los alimentos naturales y los ultraprocesados impregna estos discursos, cada uno de los cuales busca legitimar sus propias verdades.

PALABRAS CLAVE: ETIQUETADO DE ALIMENTOS • DISPUTAS DISCURSIVAS・RELACIONES DE PODER • COMUNICACIÓN ORGANIZACIONAL - ANÁLISIS DE CONTENIDO. 


\section{INTRODUÇÃO}

A lém das funções de proteger e envolver os bens, as embalagens precisam atrair visualmente a atenção dos consumidores nas gôndolas dos supermercados em meio a vários produtos da mesma categoria de diferentes fabricantes (Clement; Kristensen; Grønhaug, 2013). Configuram-se como a peça de comunicação mais relevante no estímulo do comportamento de compra por impulso (Kuvykaite; Dovaliene; Navickiene, 2009), pois impactam os consumidores no momento crucial de decisão de compra: o ponto de venda (Ampuero; Vila, 2006). Por isso, o aspecto visual do design da embalagem é um importante influenciador na avaliação dos consumidores em relação a diversos tipos de produtos, como os gêneros alimentícios (Wang, 2013). Segundo Skaczkowski et al. (2016), os consumidores costumam dar mais importância à embalagem, marca e rotulagem na escolha de alimentos e bebidas que não são considerados saudáveis em comparação com a comida in natura, uma vez que são indulgências idealmente consumidas esporadicamente.

Neste contexto, o processo decisório sobre a inserção de chamadas de advertência na rotulagem frontal de alimentos embalados no Brasil é revelador de estratégias, disputas e discursos. Para Khandpur et al. (2019), essas advertências fornecem subsídios aos consumidores para uma melhor seleção, compra e consumo de gêneros alimentícios saudáveis, ao informar no rótulo frontal quais produtos contariam com altos níveis de sódio, açúcar e gordura. Nesta visão, os alimentos considerados não saudáveis são os industrialmente processados, normalmente ultraprocessados, ou seja, alimentos prontos para consumo ou que precisam somente ser esquentados e que são produzidos a partir de substâncias extraídas de alimentos e/ou sintetizadas em laboratório (Menegassi et al., 2018). Assim, de acordo com representantes da sociedade civil, é preciso levar em conta o "grau de processamento dos alimentos" (Monteiro et al., 2016). Por outro lado, para o setor industrial, deve-se avaliar os nutrientes presentes nos alimentos para uma dieta equilibrada. Conforme Laudan (2001), foi a comida industrialmente processada que permitiu a pessoas de todas as classes sociais pagar por uma alimentação segura e nutritiva, o que melhorou a saúde dos indivíduos e aumentou a expectativa de vida de contingentes populacionais e mesmo de países inteiros.

Sato et al. (2019) listam países que já adotaram ou estudam implementar algum padrão de advertência na rotulagem frontal, como o Chile e o Canadá, e também os modelos pesquisados, por exemplo: 1) semáforo, que destaca altos e baixos níveis de nutrientes de um alimento e sua contribuição equivalente ao consumo de um adulto, ressaltando aspectos ruins com a cor vermelha e os bons com a cor verde; 2) triângulos pretos, com o aviso "alto em" para determinado nutriente. Esses e outros modelos de advertência foram considerados pela Agência Nacional de Vigilância Sanitária (Anvisa), entidade responsável pela regulamentação da rotulagem de alimentos no Brasil. Porém, o padrão aprovado foi um modelo de lupa' que não foi investigado em artigos científicos como os modelos anteriormente citados. Por exemplo, Khandpur et al. (2018) argumentam que a advertência com os triângulos pretos seria a melhor alternativa para desestimular o consumo de alimentos que os estampassem.

Isto gerou uma controvérsia sobre a influência das indústrias alimentícias nesta decisão e possíveis conflitos de interesse. Afinal, o desestímulo à compra de produtos com advertências poderia ocasionar queda na rentabilidade destas empresas. Neste sentido, a contribuição deste artigo versa sobre o debate acerca do novo padrão de rotulagem brasileira ao visibilizar os atores da sociedade civil e das indústrias alimentícias que participaram desta contenda e ouvir as versões de alguns de seus representantes em relação a este processo de aprovação.

Assim, examinamos as disputas que giram em torno do processo de aprovação da rotulagem nutricional frontal de advertência a altos níveis de sódio, açúcar adicionado e gordura saturada em alimentos embalados aprovada no final de 2020 pela Anvisa, bem como os embates de poder subjacentes por meio de entrevistas concedidas por representantes de entidades ligadas à sociedade civil e também de associações relacionadas com as indústrias alimentícias.

1 Disponível em: https://www.gov.br/anvisa/pt-br/assuntos/noticias-anvisa/2020/aprovada-norma-sobre-rotulagem-nutricional/apresentacao-rotulagem-nutricional_19a. pdf. Acesso em: 29 abr. 2021. 


\section{REFERENCIAL TEÓRICO}

Para Foucault (2015), o poder não é algo universal e estável, uma vez que é constituído historicamente nas práticas sociais, de modo que penetra na vida cotidiana dos sujeitos e se manifesta nas práticas discursivas. Assim, não se trata de repressão ou dominação do Estado ou das grandes corporações, mas dos micropoderes que se relacionam com o poder constituído e que não são localizáveis na estrutura social. Para o autor, o poder não existe senão em ato, nas relações entre os sujeitos.

O que faz com que o poder se mantenha e que seja aceito é simplesmente que ele não pesa só como uma força que diz não, mas que de fato ele permeia, produz coisas, induz ao prazer, forma saber, produz discurso. Deve-se considerá-lo como uma rede produtiva que atravessa todo o corpo social muito mais do que uma instância negativa que tem por função reprimir. (Foucault, 2015, p.45)

Neste sentido, os micropoderes gerenciam a vida dos indivíduos, controlam suas ações e servem-se de suas potencialidades ao mesmo tempo que buscam diminuir as resistências, ou seja, aumentam a utilidade econômica e reduzem a capacidade de reflexão política dos sujeitos, visto que penetram profundamente a trama da sociedade (Foucault, 2015). Cada sociedade possui seu regime de verdade: "os tipos de discurso que ela acolhe e faz funcionar como verdadeiros" (Foucault, 2015, p.52).

Para Foucault (2015), a verdade está, pois, centrada no discurso científico e nas instituições que o produzem, sendo sempre mobilizada pela produção econômica e pelo poder político. Nesta perspectiva, Kraemer et al. (2014) concebem o conceito de "poder-conhecimento", pois "o discurso que ordena a sociedade é sempre o discurso daquele que detém o conhecimento" (p.1346). 0 discurso científico enquadra-se nesta visão tanto para leigos que aceitam os efeitos do poder quanto por parte dos profissionais e cientistas que estão ligados aos sistemas de poder produtores desses discursos de verdade. Por exemplo,

a terapêutica em Nutrição, baseada em uma racionalidade em que a cura seria o restabelecimento do estado normal, atribui à alimentação saudável um conceito normativo, um valor idealizado. Trata-se de uma alimentação de caráter dietoterápico, baseada em necessidades individuais, que prescreve a moderação e o controle na ingestão de alimentos energéticos, ricos em sódio, gorduras saturadas e trans e incentiva o consumo de alimentos fontes de fibras, vitaminas e minerais, como as frutas, legumes e verduras. (Kraemer et al., 2014, p.1349)

Com efeito, os alimentos são tratados como medicamentos, o que, para Kraemer et al. (2014), separa o alimento do contexto e das práticas cotidianas dos sujeitos. Por sua vez, o Guia Alimentar para a População Brasileira procura avaliar não somente o conteúdo dos alimentos em nutrientes, mas a história e a cultura contida nos alimentos para a promoção de sistemas alimentares sustentáveis (Monteiro et al., 2016). A principal controvérsia em relação ao guia se dá por causa de sua classificação alimentar por grau de processamento, especialmente o último grupo: alimentos ultraprocessados. Para Monteiro et al. (2016), os alimentos ultraprocessados são formulações industriais que utilizam aditivos, conservantes e estabilizantes que não costumam estar presentes nas preparações caseiras, mantendo pouco ou mesmo nada do alimento in natura.

De um lado, há os que acusam as indústrias fabricantes de produtos ultraprocessados de se valerem de sua capacidade econômica para fazer que seus interesses comerciais prevaleçam (Mariath; Martins, 2020). Para as autoras, o lobby lícito é válido porque aproxima a tomada de decisão do que os grupos organizados pleiteiam, mas pode haver problemas quando existe desequilíbrio de forças entre esses grupos, com resultados que podem ser contrários ao interesse público.

Por outro lado, existem os que defendem que alimentos industrialmente processados não são parte do problema, mas da solução para termos sistemas alimentares sustentáveis no futuro (Wiseman et al., 2019). Para os autores, a indústria de alimentos teria a capacidade de inspirar uma mudança do consumidor para escolhas mais saudáveis e sustentáveis, por exemplo, ao desenvolver análogos de carne (plant-based) com ingredientes saudáveis, perfil de nutrientes equilibrado e baixo impacto ambiental em uma nova geração de alimentos processados bons para os indivíduos e para o planeta. Assim, conforme Laudan (2001), desprezar a comida industrialmente processada é problemático, tal qual os operários que abominavam as máquinas da Revolução Industrial por destruírem seu modo de vida tradicional. 


\section{METODOLOGIA}

De acordo com Bardin (2010), a análise de conteúdo objetiva superar a incerteza - ver na mensagem o que está efetivamente contido - e enriquecer a leitura ao descobrir as estruturas de que, a priori, não se tem compreensão. Trata-se de um conjunto de técnicas de análise das comunicações que vai desde o cálculo de frequências até a extração de estruturas traduzíveis em modelos quantificáveis (Bardin, 2010). Deste modo, recorre-se a esta metodologia para decupar as entrevistas realizadas com representantes de diferentes faixas do espectro da controvérsia para a identificação de regularidades, dissonâncias e posicionamentos expressos nas falas dos entrevistados sobre a definição do novo padrão brasileiro de rotulagem de alimentos embalados.

Deste modo, esta pesquisa é do tipo exploratória, por seu caráter descritivo e de apresentação de situação. Os procedimentos metodológicos para realização da análise de conteúdo são apresentados a seguir, a saber: critérios de coleta de dados primários, realização das entrevistas e tratamento de dados.

\section{Coleta de dados}

Quanto aos critérios de coleta de dados primários - seleção dos entrevistados: 1) realizou-se contato por e-mail com nove entidades atuantes no setor alimentício, favoráveis ou contrárias aos alimentos ultraprocessados, sendo que cinco concordaram em participar; 2) aquelas que responderam elegeram um representante como contato a ser entrevistado; 3 ) os participantes assinaram o Termo de Consentimento Livre e Esclarecido (TCLE) e puderam expressar seus conhecimentos e suas experiências com liberdade para manifestar-se conforme sua vontade, sem constrangimentos por parte do condutor da entrevista. Foi dada a garantia de que o nome ou dados pessoais dos participantes não seriam citados, sendo mencionado somente como "entrevistado", "colaborador" ou "representante" de determinada entidade/associação. 0 estudo recebeu aprovação do Comitê de Ética em Pesquisa da Escola Superior de Propaganda e Marketing (ESPM)².

\section{Entrevistas}

Quanto à realização das entrevistas: 1) foram realizadas de modo on-line, em março de 2021, e foram registradas em áudio. É pertinente destacar que foram feitas outras perguntas, mas neste artigo temos o recorte somente para a questão da rotulagem; 2) segundo o critério de suficiência comparativa de Orozco-Gómez e Reyes (2012), o limite de entrevistados é dado pela redundância informativa sobre o que se busca. Estipulamos quatro entrevistas como número mínimo, sendo dois depoimentos favoráveis à alimentação natural e dois favoráveis aos alimentos industrializados; 3) de um lado, obteve-se sucesso nesta empreitada, uma vez que foram feitas quatro entrevistas com entidades que apoiam a alimentação natural. São elas: o Núcleo de Pesquisas Epidemiológicas em Nutrição e Saúde Pública da Universidade de São Paulo (Nupens-USP); o Instituto Brasileiro de Defesa do Consumidor (Idec); a ACT Promoção da Saúde, em sua divisão que trata da alimentação saudável; e a Associação Brasileira de Nutrição (Asbran). Por outro lado, somente uma entidade que representa as indústrias alimentícias concordou em participar da pesquisa, a Sociedade Brasileira de Alimentação e Nutrição (Sban).

\section{Tratamento de dados}

Quanto ao desenvolvimento da análise de conteúdo das entrevistas, foi implementado o seguinte tratamento de dados: 1) organização e codificação das entrevistas em unidades de informação, resultando em uma análise lexical e de correlação dos termos com a 
utilização do software Iramuteq; 2) criação de categorias de análise por meio da análise temática, utilizada para analisar opiniões, valores, tendências e que "consiste em descobrir os núcleos de sentido que compõem a comunicação" (Bardin, 2010, p.135).

A partir da preparação de corpus textual e do processamento do software, foi possível realizar contagem da frequência de palavras, obter informações lexográficas e gerar imagens gráficas, tais como: 1) nuvem de palavras, que mostra as palavras que mais se destacaram no corpus textual; 2) análise de similitude, que possibilita compreender como as palavras recorrentes se relacionam no texto; 3) classificação hierárquica descendente (CHD), que apresenta o nível de correlação dos termos em classes de palavras (clusters); e 4) análise fatorial de correspondência (AFC), que demonstra o posicionamento dos clusters de palavras mais fortemente correlacionadas, sendo possível comparar posicionamentos entre as entidades. Ao final, obtevese a classificação dos conteúdos das entrevistas em categorias temáticas.

\section{RESULTADOS}

Foram examinadas cinco entrevistas com enfoque nas considerações sobre rotulagem, totalizando 6.875 palavras analisadas. Após o processamento dos dados pelo Iramuteq, o primeiro output a ser destacado é a nuvem de palavras (Figura 1) em que apresentamos uma comparação entre as quatro entrevistas de entidades da academia e/ou da sociedade civil e a entrevista de entidade representante da indústria alimentícia. Palavras como "gente" e "entendeu" foram excluídas por não representarem informação relevante ou serem muletas linguísticas da fala dos entrevistados que iriam poluir as representações gráficas.

Percebe-se, ao comparar as duas nuvens de palavras, que a discussão da Sban se concentra no alimento em si, no papel da indústria na alimentação e nos ingredientes. A nuvem de palavras desta entidade, à esquerda, ilustra uma premissa bastante defendida durante a entrevista, de que antes da comida industrializada as pessoas não comiam bem por uma série de dificuldades, como: transporte, conservação e sazonalidade dos alimentos. Durante a entrevista, houve menções diretas à rotulagem, mais especificamente ao clean label (indica um produto feito apenas com ingredientes reconhecíveis pelo consumidor), mas o lramuteq não as capturou porque estava programado para termos em português (ou de uso corrente, por exemplo, design).

Figura 1: À esquerda, nuvem de palavras de entrevistado da indústria alimentícia e, à direita, consolidado das outras quatro entrevistas
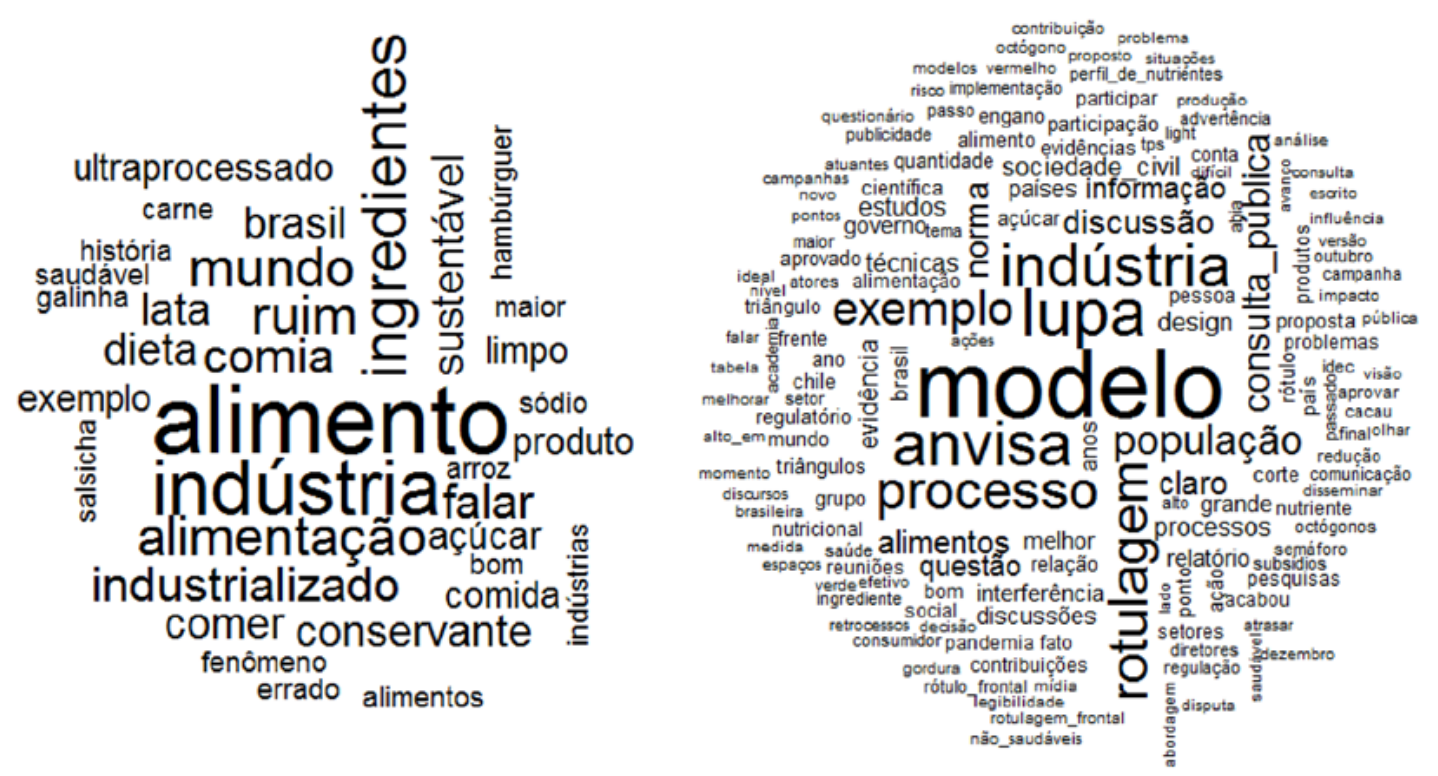

Fonte: elaborada pelos autores por meio do software Iramuteq.

Por sua vez, a nuvem de palavras da ACT, Idec, Nupens e Asbran evidencia a discussão mais focada no processo de aprovação do novo modelo de rotulagem, no papel da Anvisa, no design da lupa, triângulo e semáforo e nas possíveis interferências por parte da indústria. 
Com o propósito de compreender o modo como as palavras relacionam-se umas com as outras dentro das linhas argumentativas, efetuou-se a análise de similitude (Figuras 2 e 3), criando conjuntos de palavras separados por cores com conexões mais ou menos espessas a depender da intensidade da relação entre os clusters. Somente as palavras com três ou mais recorrências são mostradas na figura 2. Verbetes como "não" e "gente" foram retirados pelos mesmos motivos apontados na análise de nuvens de palavras.

Identificamos que há uma forte ligação entre indústria e produto no cluster superior. No conjunto verde, percebe-se que 0 entrevistado descreve que o ultraprocessado é condenado no Brasil, visto como algo errado. Relacionando com a entrevista, temos o depoimento de que a palavra "ultraprocessado" surgiu no Brasil e que é um conceito ruim que vem sendo disseminado em outros países. Por isso, entendemos que os clusters verde e azul claro estão com sobreposição no grafo, ao traçar uma relação entre alimento, exemplo e ruim.

Figura 2: Análise de similitude do entrevistado da indústria alimentícia

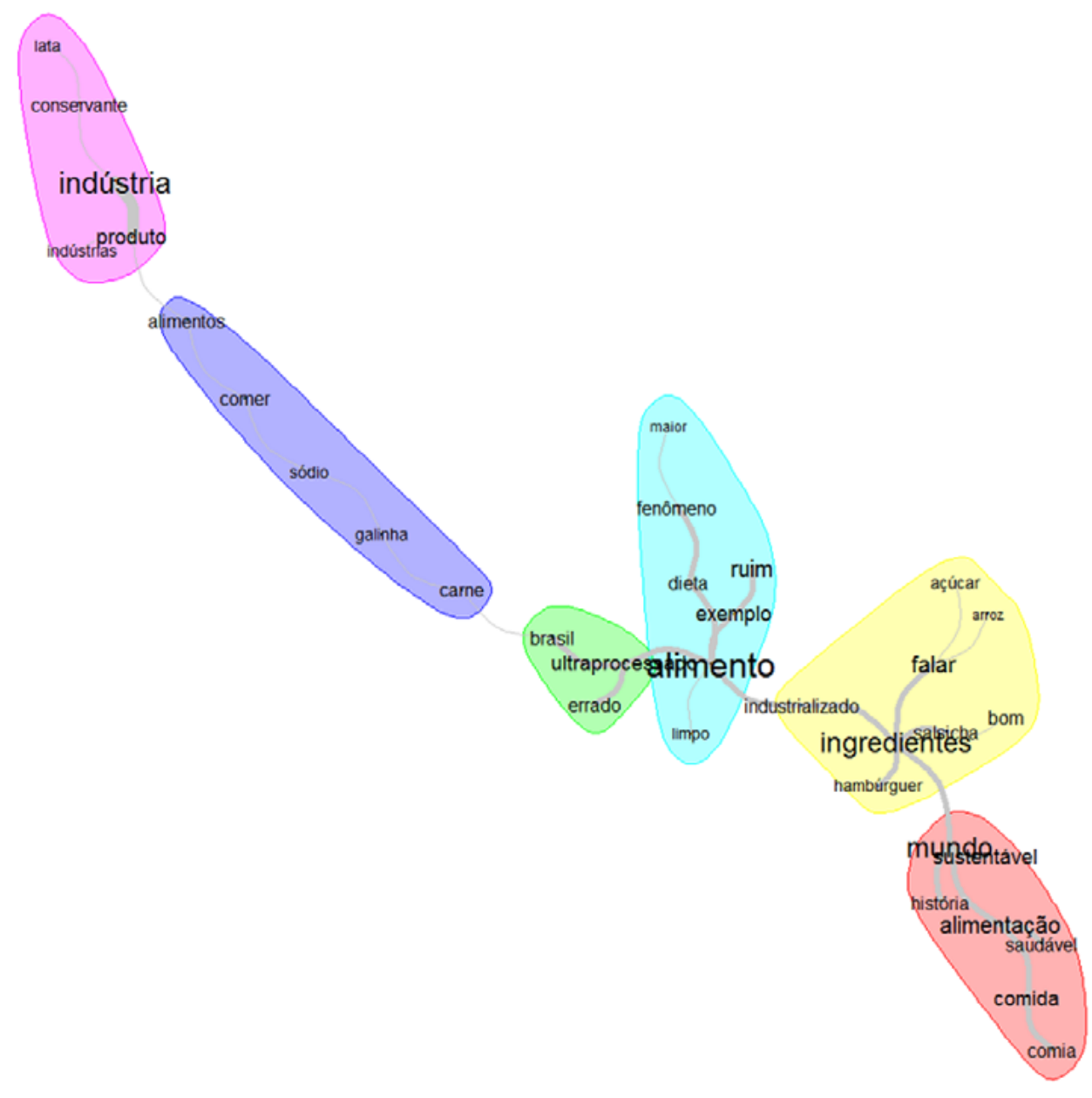

Fonte: elaborada pelos autores por meio do software Iramuteq.

Na figura 3, temos o grafo da estrutura da construção dos textos da ACT, Idec, Nupens e Asbran. Somente as palavras com seis ou mais recorrências são mostradas. Se utilizássemos um limite menor de recorrências, haveria sobreposição de palavras, o que dificultaria a leitura e compreensão do grafo.

0 cluster central, em roxo, relaciona a Anvisa a processos e discussões de propostas. A conexão com o eixo superior por via da expressão "consulta pública" e na sequência "lupa" salienta o modelo de rotulagem escolhido. Relacionando com as entrevistas, é importante destacar que o modelo de lupa aprovado pela diretoria da Anvisa não foi o padrão debatido nas consultas públicas, e que, segundo os entrevistados, um modelo diferente de lupa já havia sido objeto de alguns poucos estudos científicos e demonstrou não cumprir tão bem o papel de advertência como o de triângulos pretos. 
Figura 3: Análise de similitude das quatro entrevistas de representantes da sociedade civil

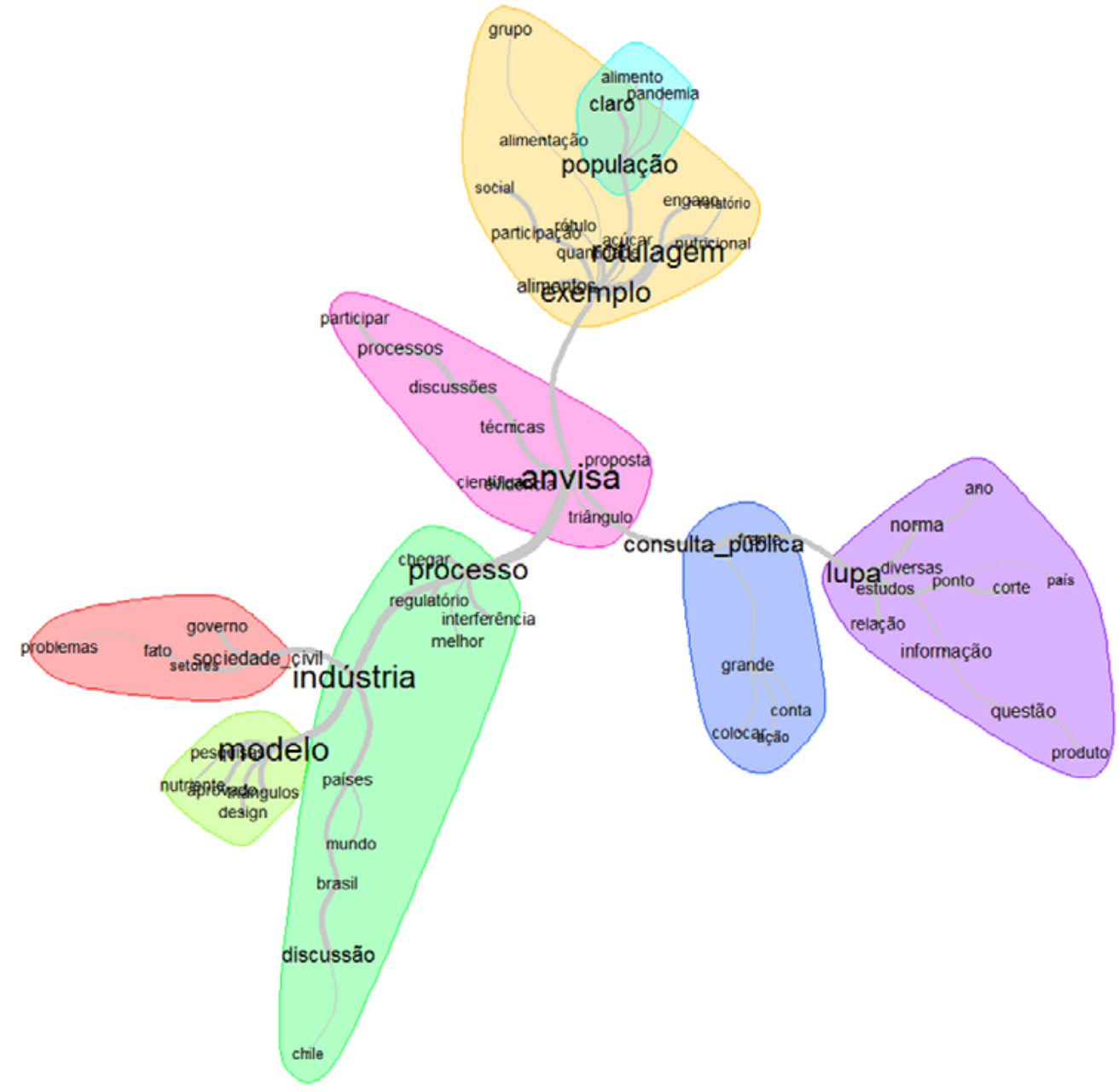

Fonte: elaborada pelos autores por meio do software Iramuteq.

Considerando o eixo da esquerda, temos a estruturação desse raciocínio, uma vez que no clusterverde claro temos a sequência "processo", "interferência" e "regulatório" que se conecta aos conjuntos vermelho "sociedade" e "governo" e verde claro "modelo", "triângulos". Recorrendo às entrevistas, os representantes da ACT e do Idec foram mais enfáticos ao relatar a possível interferência por parte das indústrias, por meio de associações, para inviabilizar o modelo dos triângulos, que seria ruim para os negócios.

Na parte superior, em que temos o clusteramarelo, evidencia-se a importância da rotulagem para demonstrar à população os atributos de determinado alimento de forma clara e evitar enganos, como na questão da quantidade de açúcar. 0 entrevistado da Asbran aborda esta questão em detalhes ao descrever que um rótulo com a informação light em açúcar não explica que o produto possui uma compensação em gordura. Sem este complemento, haveria, segundo o entrevistado, uma indução ao consumo em maior quantidade deste alimento light por se levar a crer que toda a informação foi dada ao consumidor.

Para além dos aspectos elencados, elaborou-se também por meio do Iramuteq o dendograma das cinco entrevistas reunidas (Figura 4). Este permite dividir as palavras em categorias de termos mais fortemente correlacionados, com a respectiva indicação do percentual de ocorrência das palavras de uma mesma categoria. Neste caso, o corpus textual foi dividido em duas grandes categorias, sendo que uma delas, em específico, foi subdividida em quatro ramificações. 
Figura 4: Dendograma do corpus textual das cinco entrevistas

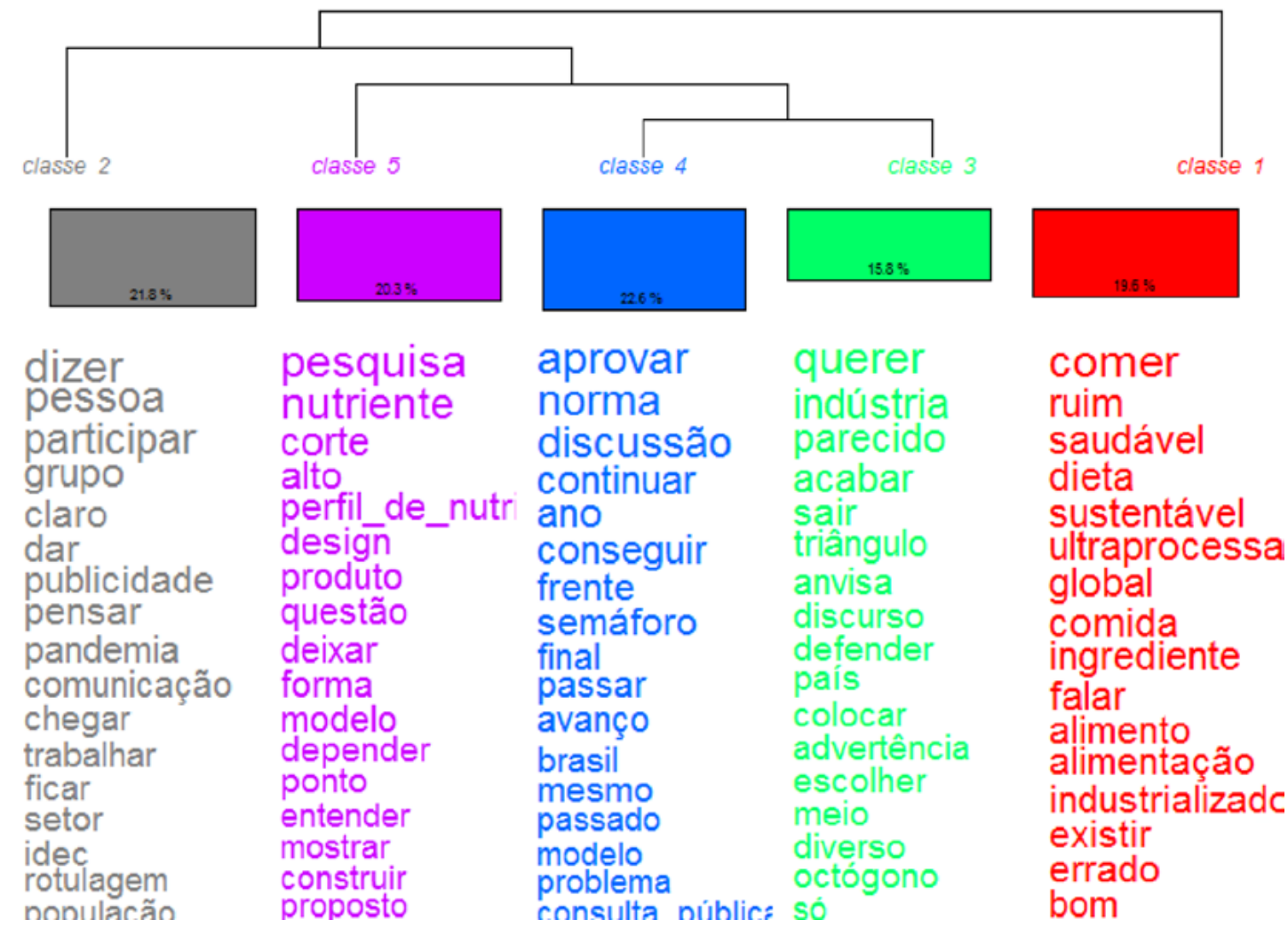

Fonte: elaborada pelos autores por meio do software Iramuteq.

Nota-se que a classe 1, que não se conecta às demais, pertence ao depoimento do representante da Sban. Podemos identificar que se trata dessa entidade por causa de palavras que já apareceram na nuvem de palavras e no grafo, como: dieta, global e sustentável. 0 gráfico 1 reforça este entendimento de dissociação da Sban frente às demais, pois, além dessa entidade estar sozinha em um quadrante, é também a única em seu eixo lexical e semântico.

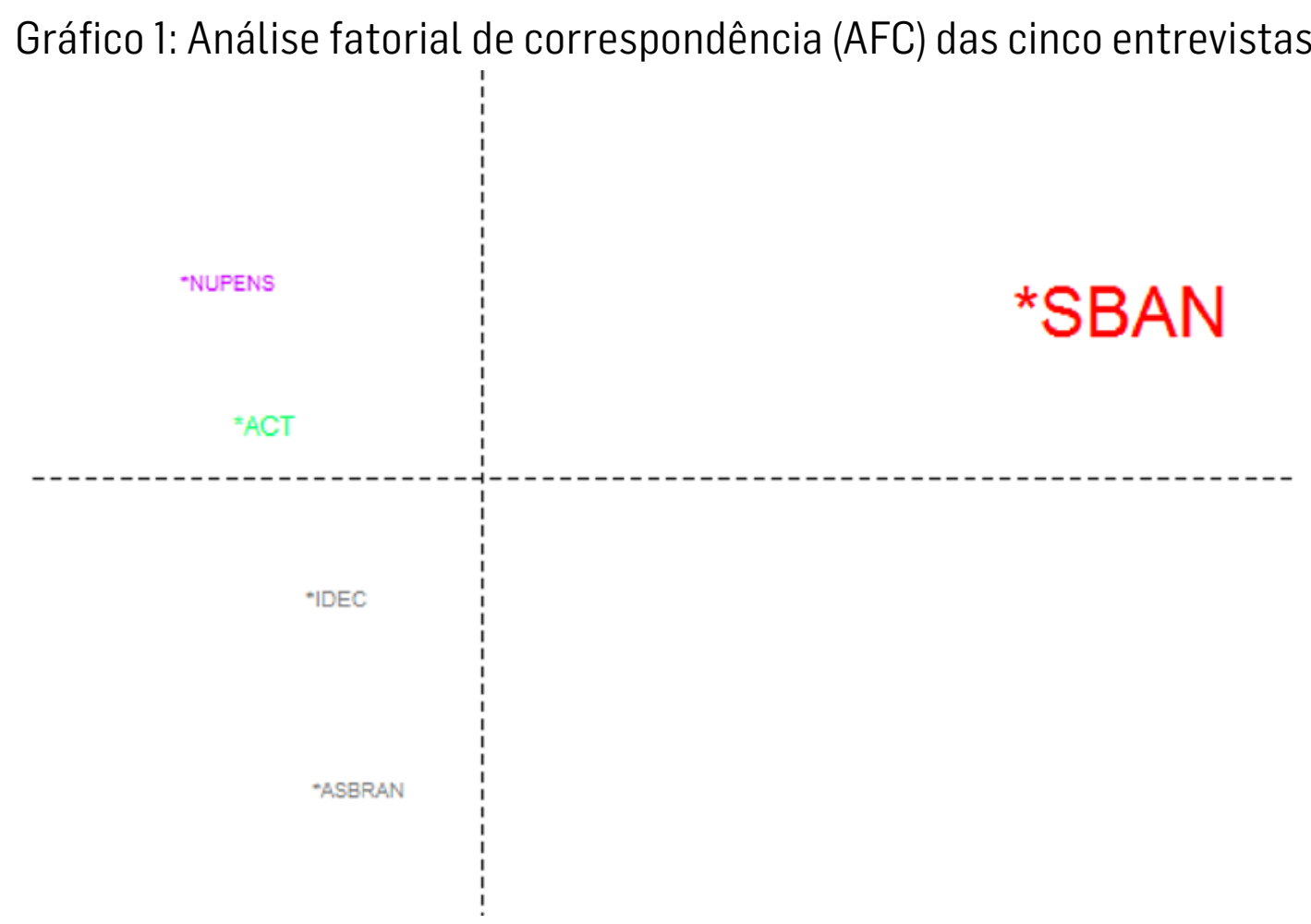

Fonte: elaborado pelos autores por meio do software Iramuteq.

Grosso modo, é possível delimitar que a classe 5 tem maior afinidade com o depoimento do representante do Nupens - pois este teve foco no perfil de nutrientes e em explicar as características de produtos "alto em" - e que a classe 3 é mais afeita ao conteúdo da entrevista do colaborador da ACT, por conta da explicação dos modelos (triângulo, octógono) e principalmente 
por ter comentado bastante sobre a questão discursiva da indústria, isto é, os seus conflitos de interesse em defesa do lucro e não da população.

Já nas classes 2 e 4 houve uma mescla dos depoimentos dos representantes do ldec e da Asbran. 0 gráfico 1 reforça esta proximidade em seus posicionamentos e conteúdo textual. É pertinente salientar que Asbran, Idec e ACT são membros da Aliança para a Alimentação Adequada e Saudável - talvez por isso compartilhem muitos posicionamentos -, e o Nupens, enquanto órgão participante da elaboração do Guia Alimentar para a População Brasileira, é como uma bússola para as entidades que defendem um padrão alimentar alinhado aos seus preceitos.

Esta construção de indicadores, juntamente com o ferramental da análise de conteúdo do tipo temática, permitiu organizar os conteúdos das entrevistas nas cinco categorias abaixo, apresentadas juntamente com um exemplo textual que ilustra 0 conteúdo de cada categoria:

- Importância do rótulo: "Enquanto tiver essa crença da praticidade, de abrir pacote. Que mesmo no mercado a gente tem essa facilidade de comprar alimentos empacotados, sem ler a rotulagem, sem ler a lista de ingredientes. Precisa ter muita consciência, com a pandemia e essa mistura de sentimentos... eu acho que não fica claro para a população". Trecho de depoimento do representante da Asbran.

- Diferentes modelos de advertência: "O semáforo nutricional, que foi o modelo que foi proposto pela indústria, que tem o vermelho, 0 amarelo e o verde, dependendo da quantidade do nutriente, já foi deixado de lado pela Anvisa, isso lá em 2018. Então, a Anvisa demonstrou que o alerta, a advertência, seria o ideal para população brasileira. Eles não colocaram um design específico, mas apresentaram alguns designs: um triângulo, um octógono, um círculo, a lupa, um retângulo". Excerto de fala do colaborador do Idec.

- Modelo aprovado: "o modelo aprovado usou uma abordagem 'alto em', que é a abordagem que identifica os alimentos que podem causar algum risco a saúde, o que foi um avanço. Porém, a Anvisa optou por um formato de design e por pontos de corte dos nutrientes que não foram totalmente validados cientificamente, porque foi um modelo de design que nunca foi estudado, não teve nenhuma pesquisa específica com aquele tipo de modelo". Fragmento da entrevista do representante do Nupens.

- Discurso contra a indústria: "Elas [as indústrias] são transnacionais. Vários países do mundo. Então, os discursos são muito parecidos. Mas eles se moldam de acordo com especificidade. [...] No caso da obesidade, por exemplo, o problema seria do indivíduo. A indústria não tem nada a ver com aquilo [...] se coloca como uma grande benfeitora da população. Quando, na verdade, são responsáveis por grandes danos, tanto à saúde quanto ao meio ambiente". Passagem do depoimento do entrevistado da ACT.

- Discurso pró-indústria: "As pessoas leigas acham que antigamente se comia bem. Ah, a comida da minha avó... Aí mais pra trás eles acham que se comia bem. E não. Isso não é verdade, isso não é fato. A antropologia alimentar mostra que lá atrás as pessoas comiam muito mal. Quem morava no campo comia mal. Comia resto de comida. [...]. Então, as pessoas morriam cedo com alimentação contaminada.". Trecho de fala do colaborador da Sban. 


\section{CONSIDERAÇÕES FINAIS}

As cinco categorias temáticas evidenciam as disputas discursivas por parte de ambos os lados da controvérsia sobre o novo modelo de rotulagem. A fala destacada na categoria "discurso pró-indústria" reforça o resultado da nuvem de palavras do representante da Sban, além de estar em conformidade ao postulado por Laudan (2001) em relação ao papel desempenhado pela indústria alimentícia de prover a todos uma comida sem contaminação, nutritiva e barata. 0 grafo da Sban salienta que os alimentos fabricados industrialmente são vistos como ruins, mas, conforme Wiseman et al. (2019), a indústria já trabalha para mudar esse entendimento no futuro por meio de uma nova geração de alimentos.

Já a categoria "discurso contra a indústria" corrobora com a literatura (Mariath; Martins, 2020) ao afirmar que as indústrias formam um grupo de interesse que desequilibra a balança em prol de seus próprios objetivos, principalmente econômicos. 0 grafo das quatro entidades da sociedade civil/academia exemplifica a recorrência desse entendimento no corpus textual analisado.

A categoria "diferentes modelos de advertência" é amparada pela literatura utilizada (Khandpur et al., 2018; Khandpur et al., 2019; Sato et al., 2019), que indicou que a melhor alternativa para advertir o consumidor não foi a escolhida. A fala do representante do Idec ressalta que a proposta da indústria foi logo descartada, por dar margem a interpretações de que 0 semáforo seria mais um elemento persuasivo da embalagem.

A categoria "importância do rótulo" tem fundamento na literatura apresentada anteriormente (Skaczkowski et al., 2016; Wang, 2013). Outros estudos, como o de Wansink e Chandon (2006), demonstram a importância das informações do rótulo: no caso, mensagens de baixo teor de gordura aumentam a ingestão de alimentos durante uma única refeição em até 50\%, reduzindo a sensação de culpa ao aumentar a percepção da porção que se pode comer, fato que ocorre principalmente nas pessoas com sobrepeso. 0 depoimento destacado nesta categoria do colaborador da Asbran traz a preocupação sobre a compreensão do que está escrito no rótulo e na lista de ingredientes. A inquietação em relação ao uso correto destas informações e seu entendimento também se evidencia no grafo das quatro entidades, no eixo da esquerda.

Por sua vez, a categoria "modelo aprovado" aponta que foi um avanço a Anvisa aprovar algum tipo de advertência no rótulo frontal de alimentos embalados, segundo evidenciado pelo grafo em seu eixo esquerdo e também pela classe 4 do dendograma. Embora as quatro entidades - Asbran, Idec, ACT e Nupens - indiquem não ter sido a melhor alternativa justamente pela possível interferência da indústria alimentícia para que o modelo dos triângulos não fosse aprovado, conforme apontado na nuvem de palavras.

Estas categorias reverberam para além do rótulo e recaem sobre as dinâmicas que Foucault (2015) identificou no poder, ou seja, que está presente nas práticas sociais cotidianas, produzindo discursos e verdades. A controvérsia entre comida natural versus alimento ultraprocessado permeia os discursos de todas as entidades analisadas, na medida em que desejam ser as portadoras do poder-conhecimento para legitimar seus discursos sobre o que é um alimento saudável - composição nutricional ou grau de processamento. Considerando que o discurso é uma modalidade instrumental do poder, as entidades envolvidas na controvérsia analisada disputam o poder-conhecimento de dizer aquilo que funciona como verdade.

Além disso, cabe ressaltar que as relações de poder se expressam como "modos de ação complexos sobre a ação dos outros" (Revel, 2005, p.67). Desse modo, a controvérsia analisada revela disputas pela manutenção de privilégios/dominância por parte da indústria de alimentos ultraprocessados; e disparidades econômicas existentes entre os mercados de alimentos naturais e ultraprocessados. A controvérsia também evidencia o lugar ocupado por ambos no processo produtivo, descortinando as complexas relações de poder que emergem nas disputas entre alimentos natural e ultraprocessado e que protagonizam a produção de verdade sobre o que é saudável ou não. 
0 representante da Sban possui elementos da terapêutica dos alimentos que Kraemer et al. (2014) indicam estar presente no discurso dietoterápico em favor dos nutrientes. Os representantes da sociedade civil examinam que a indústria utiliza mensagens nutricionais na rotulagem frontal de alimentos embalados como uma tática para aumentar as vendas, conforme salienta a análise de similitude, e para a ingestão de maior quantidade de comida, como no caso de mensagens "baixo em" (Wansink; Chandon, 2006) ou "rico em vitaminas" e similares. Ao mesmo tempo, ACT, Idec, Nupens e Asbran defendem a classificação de grau de processamento dos alimentos (Monteiro et al., 2016) como a mais adequada e saudável.

Uma limitação do estudo é não ter outros representantes das indústrias alimentícias. A Associação Brasileira das Indústrias Alimentícias (Abia), o Instituto de Tecnologia de Alimentos (Ital), a Associação Brasileira da Indústria de Alimentos para Fins Especiais e Congêneres (Abiad) e a Unilever foram contatados, mas não responderam ou ainda estão analisando o pedido de entrevista até a data de submissão deste artigo.

Estudos futuros podem direcionar esforços ao entrevistar somente representantes da sociedade civil ou da indústria, especialmente quando o novo padrão de rotulagem entrar em vigor. Pesquisas comparadas são pertinentes desde já ao contrastar a embalagem aprovada pela Anvisa com as alternativas anteriores de advertência nos moldes do experimento controlado randomizado realizado por Khandpur et al. (2018), que confrontou o modelo de semáforo com o dos triângulos pretos. Outra possibilidade é realizar a comparação entre o modelo aprovado e os modelos de advertência anteriores em experimentos que meçam o rastreamento ocular através do aparelho eye-tracker para quantificar a atenção visual dos participantes.

Pode-se, então, contemplar o objetivo desta pesquisa, que foi examinar os embates sobre o processo de aprovação do novo modelo de rotulagem nutricional frontal brasileiro, assim como as questões de poder envolvidas. Os representantes das cinco entidades tiveram a oportunidade de fazer ponderações, expondo livremente seus argumentos. Não houve a pretensão de julgar qual o discurso de verdade seria o correto do ponto de vista da nutrição humana, mas sim explorar contextos, práticas discursivas e produção de sentidos que circulam na sociedade brasileira em uma peça de comunicação tão presente no cotidiano dos sujeitos: a embalagem.

\section{REFERÊNCIAS}

AMPUERO, Olga; VILA, Natalia. Consumer perceptions of product packaging. Journal of Consumer Marketing, Bingley, v.23, n.2, p.102-114, 2006.

BARDIN, Laurence. Análise de conteúdo. Lisboa: Edições 70, 2010.

CLEMENT, Jesper; KRISTENSEN, Tore; GRøNHAUG, Kjell. Understanding consumers' in-store visual perception: the influence of package design features on visual attention. Journal of Retailing and Consumer Services, Amsterdam, v.20, n.2, p.234-239, 2013.

FOUCAULT, Michel. Microfísica do poder. Rio de Janeiro: Paz e Terra, 2015.

KHANDPUR, Neha et al. Choosing a front-of-package warning label for Brazil: a randomized, controlled comparison of three different label designs. Food Research International, Amsterdam, v.121, p.854-861, 2019.

KHANDPUR, Neha et al. Are front-of-package warning labels more effective at communicating nutrition information than traffic-light labels? A randomized controlled experiment in a Brazilian sample. Nutrients, Basel, v.10, n.6, p.1-15, 2018. 
KRAEMER, Fabiana et al. 0 discurso sobre a alimentação saudável como estratégia de biopoder. Physis: Revista de Saúde Coletiva, Rio de Janeiro, v.24, p.1337-1360, 2014.

KUVYKAITE, Rita; DOVALIENE, Aiste; NAVICKIENE, Laura. Impact of package elements on consumer's purchase decision. Economics and Management, Oxford, n.14, p.441-447, 2009.

LAUDAN, Rachel. A plea for culinary modernism: why we should love new, fast, processed food. Gastronomica: The Journal of Food and Culture, Berkeley, v.1, n.1, p.36-44, 2001.

MARIATH, Aline; MARTINS, Ana Paula. Atuação da indústria de produtos ultraprocessados como um grupo de interesse. Revista de Saúde Pública, São Paulo, v.54, p.1-10, 2020.

MENEGASSI, Bruna et al. A nova classificação de alimentos: teoria, prática e dificuldades. Ciência \& Saúde Coletiva, Rio de Janeiro, v.23, p.4165-4176, 2018.

MONTEIRO, Carlos A. et al. NOVA. The star shines bright. World Nutrition, Peacehaven, v.7, p.28-40, 2016.

OROZCO-GÓMEZ, Guillermo; REYES, Rodrigo. Una coartada metodológica: abordajes cualitativos en la investigación en comunicación, medios y audiencias. Mexico: Tintable, 2012.

REVEL, Judith. Michel Foucault. conceitos essenciais. São Carlos: Claraluz, 2005.

SATO, Priscila et al. Consumers' opinions on warning labels on food packages: a qualitative study in Brazil. PLoS One, San Francisco, v.14, n.6, p.1-17, 2019.

SKACZKOWSKI, Gemma et al. The effect of packaging, branding and labeling on the experience of unhealthy food and drink: a review. Appetite, Amsterdam, v.99, p.219-234, 2016.

WANG, Edward. The influence of visual packaging design on perceived food product quality, value, and brand preference. International Journal of Retail \& Distribution Management, Bingley, v.41, n.10, p.805-816, 2013.

WANSINK, Brian; CHANDON, Pierre. Can "low-fat" nutrition labels lead to obesity? Journal of Marketing Research, Chicago, v.43, n.4, p.605-617, 2006.

WISEMAN, Sheila et al. Future food: sustainable diets for healthy people and a healthy planet. International Journal of Nutrology, Catanduva, v.12, n.1, p.23-28, 2019.

Artigo recebido em 29.04.2021 e aprovado em 09.08.2021. 